\title{
ТРАНСГЕННАЯ ПТИЦА - СОЗДАНИЕ И ОБЛАСТИ ПРИМЕНЕНИЯ (обзор)
}

\section{Л.Г. КОРШУНОВА, Р.В. КАРАПЕТЯН, О.Ф. ЗИАДИНОВА, В.И. ФИСИНИН}

Технологии трансгенеза в птицеводстве могут быть направлены на улучшение качественных и количественных характеристик продукции (Л.Г. Коршунова, 2011), создание птицы, генетически устойчивой к инфекционным заболеваниям и продуцирующей с яйцом рекомбинантные белки различного назначения (D. Сао с соавт., 2015). Для получения трансгенных животных чаще всего прибегают к микроинъекции ДНК в зиготы. Однако особенности размножения птиц создают серьезные проблемы для исследователей. Курица образует в сутки одну оплодотворенную яйцеклетку, которая очень велика и нежна для каких-либо манипуляций с ней. Для нормального эмбрионального развития ей необходимы третичные оболочки - белковая, подскорлупные и скорлупа. Дробление куриной яйцеклетки начинается уже в белковом отделе яйцевода, а в свежеснесенном яйце имеется 50-60 тыс. клеток. Первая трансгенная птица была получена с помощью ретровирусных векторов. В нормальных условиях ретровирусы сами включаются в геномную ДНК хозяина и реплицируются. На сегодняшний день трансгенные куры и перепела получены посредством ретровирусного (D.W. Salter с соавт., 1989; R.A. Bosselman с соавт., 1989; L.B. Crittenden с соавт., 1992) и лентивирусного трансгенеза (Н.A. Kaleri с соавт., 2011; A.H. Seidl с соавт., 2013; Н.А. Волкова с соавт., 2015). Эффективные технологии модификации генома кур и перепелов продолжают разрабатываться. К ним относят метод ZFNs (zinc finger nucleases), TALENs (transcription activator-like effector nucleases) (T.S. Park c coabt., 2014), CRISPR/Cas9 (I. Oishi с соавт., 2016; Q. Zuo с соавт., 2016). Технология CRISPR/Cas9 позволяет достичь дальнейшего прогресса в генетических манипуляциях с птицей и создания линий с отредактированным геномом (N. Veron с соавт., 2015). Птичьи эмбрионы, главным образом эмбрионы курицы (Gallus gallus domesticus) и перепела (Coturnix japonica), более века служили моделью в эмбриологических исследованиях позвоночных. Современные целенаправленные генные манипуляции на эмбрионе цыпленка как модели in vivo стали возможны благодаря системе редактирования CRISPR/Cas9 (V. Morin с coaвT., 2017). K другим методам создания трансгенных птиц относится получение химер при подсадке в эмбрионы чужих эмбриональных клеток в качестве переносчиков чужеродной ДНК (J.N. Petitte с соавт., 1990; J.Y. Han с соавт., 2017; Н.А. Волкова с соавт., 2017). Трансгенез с использованием сперматозоидов для доставки в зиготу инородного генетического материала представляется весьма заманчивым, поскольку искусственное осеменение широко используется в птицеводстве (Е. Harel-Markowitz с соавт., 2009; А.В. Самойлов с соавт., 2013). Использование спермиев для переноса чужеродной ДНК в яйцеклетки птиц в сочетании с технологией CRISPR/Cas9 позволит значительно сократить время и ресурсы, затрачиваемые на создание трансгенных особей с целевым изменением генотипа в первом поколении, что открывает новые возможности для селекции (С.А. Соорег с соавт., 2017). Классической технологией безвирусного трансгенеза остается микроинъекция ДНК в зиготу. Метод включает прямую инъекцию генной конструкции в цитоплазму свежеоплодотворенной яйцеклетки курицы с последующей инкубацией до вылупления. Яйцеклетка для инъекции должна быть получена сразу после оплодотворения, следовательно, ее движение вниз по яйцеводу прерывается. Далее используется специально разработанная система культивирования (С. Mather, 1994). Другой вариант микроинъекций ДНК в яйцеклетку птиц предусматривает образование ее третичных оболочек естественным образом в половых путях птицы. В основе метода лежит хирургическая операция, которая обеспечивает доступ к яйцеклетке, инъекцию в нее ДНК и имплантацию обратно в яйцевод для формирования полноценного инкубационного яйца (Р.В. Карапетян, 1995). Так были созданы трансгенные куры и перепела с различными генными конструкциями (Р.В. Карапетян, 1996; Л.Г. Коршунова с соавт., 2013).

Ключевые слова: трансгенез, птица, ретровирусы, микроинъекции, примордиальные клетки, сперматозоиды, редактирование генома.

В эпоху развитого промышленного птицеводства количество пород птицы, используемых в производстве, существенно сократилось. Наиболее рентабельными стали генотипы, отобранные для определенных условий, однако при изменении требований рынка возникает экономическая необходимость в породах и линиях с новыми свойствами.

Мощные средства для изменения живых организмов предоставляет генная инженерия. Поскольку для интеграции чужеродных генов не суще- 
ствует видового барьера, могут быть созданы трансгенные особи заданного типа, которые невозможно получить классическими селекционными методами. Трансгенные организмы отличаются от природных тем, что получены методами генной инженерии и содержат в своем геноме чужеродный генно-инженерный материал. Они способны к воспроизводству и передаче искусственно измененного генетического материала потомству. Технологии трансгенеза в птицеводстве могут быть направлены на улучшение качественных и количественных характеристик продукции, создание птицы генетически устойчивой к инфекционным заболеваниям, и птицы-продуцента рекомбинантных белков различного назначения с яйцом. Для практического использования трансгенная птица должна иметь фенотип, превосходящий уровень, уже достигнутый в птицеводстве. Такими признаками могут быть увеличение скорости роста, улучшение конверсии корма, повышение яйценоскости, уменьшение ожиренности тушки, повышением устойчивости к заболеваниям и т.д. В сравнении с традиционными селекционными методами, когда для переноса нужного гена от одной линии птицы к другой требуются последующие многочисленные возвратные скрещивания для удаления ненужных генов, наследуемых при естественной половой гибридизации, трансгенез дает многолетний выигрыш во времени. В отличие от традиционной селекции, трансгенез предоставляет уникальную возможность получать птицу, продуцирующую и накапливающую в яйце полезные для медицинских и промышленных целей белки, что также может иметь широкое практическое применение (1-4).

Цель настоящего обзора - обобщение данных о биоинженерных методах создания и возможных областях применения трансгенной птицы.

Исследования по разработке практичных способов трансгенеза на птице продолжаются с момента создания трансгенной мыши в 1980-х годах. Первые манипуляции с зиготой цыпленка положили начало развитию более успешных технологий (5). В настоящее время существуют несколько методов генетической модификации организма. Чаще всего прибегают к микроинъекции ДНК в яйцеклетки. При этом стремятся к тому, чтобы трансген содержался во всех клетках организма и обязательно - в половых (для передачи потомству). Гены переносят на самых ранних этапах развития организма, в том числе на стадии зиготы. Однако особенности размножения птиц создают здесь серьезные проблемы. Курица образует в сутки одну оплодотворенную яйцеклетку, которая очень велика и нежна для каких-либо манипуляций. Для нормального эмбрионального развития ей необходимы третичные оболочки - белковая, подскорлупные и скорлупа. Дробление куриной яйцеклетки начинается уже в белковом отделе яйцевода, а в свежеснесенном яйце имеется 50-60 тыс. клеток.

Первую трансгенную птицу получили с помощью ретровирусных векторов. Ретровирусы стали главными претендентами на роль переносчиков генов, поскольку в нормальных условиях сами включаются в геномную ДНК хозяина и реплицируются. Многие исследователи пытались внести чужеродные гены в зародышевую линию, инфицируя эмбрионы как способными к репликации, так и утратившими эту способность ретровирусными векторами $(6,7)$. Частота успешное встраивание трансгена в этих опытах составляла от 0,8 до $5 \%$. Положительный результат по переносу генетического материала в зародышевую линию дало введение рекомбинантного вектора лейкоза птиц в бластодерму инкубируемых куриных эмбрионов (8, 9). С рекомбинантным вирусом были созданы полные трансгены (10-12).

B pаботе S.H. Lee с соавт. (3) изучалась возможность использования цыплят в качестве биореактора для получения активатора плазмино- 
гена урокиназного типа ( $h u P A)$ человека. Рекомбинантный ген $h u P A$ под контролем промотора вируса саркомы Rous вводили в свежеснесенные куриные яйца на стадии X с использованием ретровирусных векторов на основе вируса лейкоза мышей. В общей сложности 38 цыплят из 573 яиц, инъецированных вирусом, вылупились и содержали ген $h u P A$ в разных частях тела. Транскрипт мРНК гена $h u P A$ присутствовал в различных органах, включая кровь и яйцеклетку, и был зародышевой линией, передаваемой следующему поколению. Содержание активного белка $h u P A$ в крови трансгенной курицы было в 16 раз выше, чем у нетрансгенной $(\mathrm{p}<0,05)$. Экспрессия белка $h u P A$ в яйцах увеличилась с 7,82 МЕ/яйцо в поколении

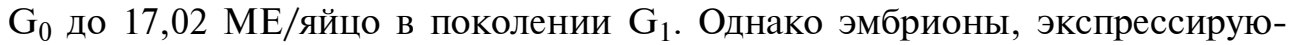
щие $h u P A$, имели сниженную выживаемость и выводимость на 18-е и 21-е сут инкубации. У трансгенных цыплят кровь свертывалась гораздо медленнее, чем у нетрансгенных аналогов $(\mathrm{p}<0,05)$. Кроме того, у взрослых трансгенных петухов снижалась фертильность (p < 0,05): объем эякулята, концентрация и жизнеспособность сперматозоидов уменьшались. В совокупности полученные данные позволяют предположить, что трансгенных цыплят $h u P A$ можно успешно получать с помощью ретровирусной векторной системы. Таких цыплят можно использовать как биореактор при производстве фармакологического препарата $h u P A$ для лечения сосудистых заболеваний, а также при изучении индуцированного $h u P A$ кровотечения и других нарушений. Активатор плазминогена урокиназного типа (uPA; Swiss-Prot: Р00749) - индуцибельная сериновая протеаза (ЕС 3.4.21.73) найдена в крови и внеклеточном матриксе, играет важную роль в фибринолизе, внеклеточном протеолизе и ремоделировании тканей.

При трансгенезе цыплят были выявлены преимущества использования вирусного вектора, несущего собственную интегразу, который может быть применен к эмбрионам в только что снесенных яйцах. Это легло в основу более эффективного метода с применением лентивирусных векторов (13-16). S.J. Вуиn с соавт. (4) использовали лентивирусные векторы для создания трансгенных цыплят, которые экспрессируют ген extracellular superoxide dismutase человека (hEC-SOD). Рекомбинантные лентивирусы вводили в подзародышевую полость свежеотложенных яиц. Затем эмбрионы инкубировали до вылупления с использованием фаз II и III системы культуры суррогатной оболочки ех vivo. Из 158 таких эмбрионов вылупились 16 цыплят $\left(\mathrm{G}_{0}\right)$. У одного из них методом ПЦР идентифицировали трансген в клетках зародышевой линии, формирующих половые клетки. Эту трансгенную птицу $\left(\mathrm{G}_{0}\right)$ скрестили с обычной и в результате получили двух трансгенных цыплят $\left(\mathrm{G}_{1}\right)$. У трансгенных кур $\mathrm{G}_{2}$ белок hEC-SOD coдержался в яичном белке и проявлял антиоксидантную активность.

Возможность манипулировать экспрессией генов при создании трансгенных куриных эмбрионов с помощью вирусных векторов оказалась полезной для анализа функций генов в тканях. Современные технологии трансгенеза с использованием лентивирусных векторов имеют значительный потенциал для генетических исследований на эмбрионах и взрослой птице. Одна из главных проблем в эмбриогенезе позвоночных состоит в том, чтобы понять, как в органах, состоящих из многих типов клеток, координируется дифференцировка и полное анатомическое развитие, и как различия в экспрессии генов влияют на фенотип. Эти и многие другие вопросы могут быть решены благодаря линиям трансгенной птицы $(2,17)$.

На сегодняшний день на птице применяется ретровирусный и лентивирусный трансгенез. Лентивирусные векторы успешно использованы для создания нескольких трансгенных линий кур и перепелов (5, 18-21). 
Разработка этой технологии продолжается $(22,23)$. Однако, несмотря на эффективность вирусной трансдукции, существует много препятствий для ее применения из-за относительно низких и переменных частот передачи трансгена по зародышевой линии, а также проблем безопасности при использовании вирусных векторов. Следовательно, получение трансгенной птицы невирусными технологиями остается необходимым условием применения трансгенеза в практике птицеводства $(24,25)$.

В настоящее время существуют и продолжают разрабатываться эффективные технологии модификации генома: метод zinc finger nucleases (ZFNs - «цинковые пальцы»), TALENs (transcription activator-like effector nucleases) (26), CRISPR/Cas9 (clustered regularly interspaced short palindromic repeats - короткие палиндромные повторы, регулярно расположенные группами) $(27,28)$. Все приемы геномной инженерии доступны на птице.

Возможности и последствия применения CRISPR/Cas9 активно изучаются (29). CRISPR/Cas9 представляет собой революционную систему редактирования генома, дающую мощный инструментарий для изучения молекулярных механизмов, регулирующих развитие (30-32). Последние достижения с использованием программируемых нуклеаз существенно повысили эффективность внесения точных изменений в геномы эукариотических клеток. Технологий редактирования генома позволяет расширить знания о генетических заболеваниях и создавать более точные модели патологических процессов (33). Особенно заманчива перспектива прямой коррекции генетических мутаций в пораженных тканях и клетках для лечения заболеваний, не поддающихся традиционной терапии (34). CRISPR/Cas9 может быть использована для ускорения прогресса в генетических манипуляциях с птицей и создания линий с отредактированным геномом (35).

Отметим, что благодаря сходству в общем онтогенезе и закономерностях экспрессии генов птица может служить превосходной моделью для исселдования генетических, молекулярных и биохимических процессов у млекопитающих, включая человека. Более века эмбрионы птиц, в основном курицы (Gallus gallus domesticus) и перепела (Coturnix japonica), были основой изучения эмбриологии позвоночных, движения клеток в морфогенезе, механизмов индукции и дифференцировки, патогенеза эмбриональных заболеваний, токсикологии. Трансгенные птицы остаются одним из мощнейших инструментов исследований в биотехнологии.

Целенаправленные генетические манипуляции на эмбрионе цыпленка как модели in vivo стали возможны благодаря системе CRISPR/Cas9 (36-39). S. Gandhi с соавт. (40) оптимизировали CRISPR/Cas9 за счет трехступенчатой стратегии, примененной на ранних эмбрионах. Во-первых, авторы использовали Cas9 с двумя сигнальными последовательностями для улучшения ядерной локализации. Во-вторых, благодаря модифицированной PHK (gRNA) не происходило преждевременного прекращения транскрипции, а взаимодействия Cas9-gRNA были стабильными. В-третьих, задействованный специфичный для цыплят промотор U6 обеспечивал в 4 раза более высокую экспрессию gRNA, чем человеческий U6. Для быстрого in vivo скрининга gRNAs также создали клеточную линию куриных фибробластов, экспрессирующих Cas9. Для доказательства принципа авторы провели электропорационные исследования потери функции в раннем эмбрионе цыпленка при белковом нокауте Pax7 и Sox10 - ключевых факторов транскрипции с известной ролью в развитии нервного гребня. Было показано, что CRISPR/Cas9-опосредованная делеция вызывает утрату соответствующих белков и транскриптов. Результаты подтвердили полез- 
ность оптимизированного метода CRISPR/Cas9 для целевого нокаута генов в куриных эмбрионах воспроизводимым, надежным и специфичным способом (40). CRISPR/Cas9 можно совмещать с другими методами изучения функции гена на куриных и перепелиных эмбрионах, например с электропорацией (в частности, для целенаправленного редактирования генов мочеполовой системы птиц) $(41,42)$.

Среди других методических подходов для безвирусного трансгенеза у птиц можно отметить получение химер при подсадке чужих клеток в эмбрионы. Выделяют клетки ранней бластодермы или примордиальные клетки, инъецируют в их ядра чужеродную ДНК, затем клетки имплантируют в эмбрионы, где они приживаются и делятся (43-47). Так, J.N. Petitte c соавт. (43) из эмбрионов цыплят линии Barred Plymouth Rock (имеет черный пигмент в перьях из-за рецессивного аллеля в I локусе) получили бластодермальные клетки и ввели их в подзародышевую полость эмбрионов от инбредной линии Dwarf White Leghorns с белыми перьями из-за доминантного аллеля в I локусе. Из 53 таких эмбрионов линии Dwarf White Leghorn шесть (11,3\%) оказались фенотипическими химерами по цвету пера, из них один (петушок) дожил до вылупления. У реципиентов распределение черных перьев варьировало и не ограничивалось какой-либо специфической областью, хотя в одном случае они преобладали на голове. Этого соматически химерного петуха скрестили с несколькими курицами Barred Plymouth Rock, чтобы оценить степень включения донорских клеток в семенники. Из полученных 719 цыплят два были фенотипически Barred Plymouth Rocks. То есть клетки, способные к превращению в клетки зародышевой линии, передались реципиентам. Фингерпринт ДНК (DNA fingerprint technique) из крови и спермы зародышевых химер показал, что обе эти ткани отличались от тканей инбредной линии Dwarf White Leghorns. Таким же образом получили соматические химеры и химеры зародышевой линии $(43,48,49)$. Химерных особей выращивали и отводили от них потомство. Некоторая часть потомков оказывалась трансгенной.

Эти и аналогичные работы (20, 50-54) показывают, что выделение, перенос и внедрение примордиальных зародышевых клеток может применяться для получения трансгенов в птицеводстве. Однако описанная технология (43) достаточно сложна и затратна. Современный прогресс в выделении примордиальных зародышевых клеток и культивировании открывает новые возможности для репродуктивных биотехнологий в птицеводстве (55-57). Продолжают разрабатываться методические приемы переноса чужеродной ДНК с эмбриональными клетками (в том числе, с использованием CRISPR/Cas9). Taк, Y. Nakamura с соавт. (58) показали, что рентгеновское облучение уменьшало количество эндогенных примордиальных зародышевых клеток и увеличивало передачу перенесенных примордиальных зародышевых клеток у химерных цыплят. Уменьшение числа эндогенных примордиальных зародышевых клеток возможно также при применении бусульфана $(59,60)$. Непосредственно в семенники стерилизованных взрослых петухов трансплантировали генно-модифицированные примордиальные зародышевые клетки. Показана их способность к созреванию в функциональные сперматозоиды и восстановление спермиогенеза (61).

Трансгенез с помощью сперматозоидов как векторов доставки в зиготу инородного генетического материала выглядит весьма заманчиво, поскольку искусственное осеменение широко применяется в птицеводстве. Проведены исследования по применению спермиев в качестве вектора доставки чужеродной ДНК в зиготы кур. Было показано, что липофектин 
взаимодействует с ДНК, образовывая липид-ДНК-комплексы, которые могут соединиться с плазматической мембраной клетки, способствуя попаданию ДНК внутрь клетки. При применениии липофектина 51,6\% спермиев петуха показали содержание экзогенной ДНК. При искусственном осеменении кур спермиями, трансфецированными с применением липофектина, экзогенная ДНК наблюдалась в бластодерме 67\% яиц. Однако присутствия чужеродной ДНК в геноме вылупившихся цыплят не обнаружили, хотя показали ее эписомную интеграцию. Для повышения эффективности трансфекции с помощью спермиев (sperm-mediated gene transfer, SMGT) метод дополнили применением ферментов рестрикции (restriction enzyme mediated integration, REMI). Линейная ДНК совместно с рестриктазой проникает в клетку-мишень посредством липофекции или электропорации. Ожидается, что рестриктаза специфически режет геномную ДНК для облегчения интеграции экзогенной ДНК с комплементарными липкими концами. Липофекция плазмидной ДНК с ферментом рестрикции считается высокоэффективным методом получения трансфицированных сперматозоидов для искусственного осеменения (62). С применением липосом методом искусственного осеменения трансфицированной спермой созданы куры с геном гранулоцитарного колониестимулирующего фактора человека. Доля трансгенных цыплят составила 33,3 \%, частота наследования чужеродного гена $-37,5$ \% (63).

С целью использования спермиев петухов в качестве векторов была изучена проницаемость мембран спермиев при различных режимах электропорации. Определен диапазон физико-химического воздействия, в пределах которого наблюдается образование пор в оболочке спермиев, а сами спермии сохраняют подвижность. Показано повышение количества красителя трипанового синего, осаждаемого со спермиями петуха после электропорации, при увеличении числа электрических импульсов и снижении осмолярности среды электропорации. Определены параметры, изменение которых позволяет увеличить эффективность электропорации (64). Однако пассивная передача невирусных конструкций через сперму петуха не всегда приводит к появлению трансгенных особей (65). Хотя на птицах показан успешный перенос экзогенного гена при помощи сперматозоидов, работ, в которых при этом наблюдалась экспрессия чужеродного гена, мало. Предполагается, что если ДНК не интернализирована в ядро сперматозоида, а только доставлена им в цитоплазму яйцеклетки, то копии ДНК в форме плазмиды обнаруживаются в ранних эмбрионах, но не выявляются у цыплят.

Невозможность получать стабильные и разнообразные модификации посредством переноса генов сперматозоидами (SMGT) привела к необходимости поиска других технологий. L. Wang с соавт. (66) успешно выделили зародышевые гаплоидные стволовые клетки (haploid embryonic stem cells, haESCs) с геномом высокоспециализированных гамет. Они могут стабильно поддерживать гаплоидию (через периодическую сортировку клеток, основанную на количестве ДНК), самообновление и плюрипотентность в перевиваемой клеточной культуре. В частности, haESCs, полученные из андрогенетических гаплоидных бластоцист (androgenetic haploid blastocysts, AG-haESCs), несущих только геном сперматозоидов, могут обеспечивать генерацию SC (semi-cloned) животных посредством инъекций в ооциты. Примечательно, что после удаления импринтированных контрольных областей H19-DMR (дифференциально метилированный участок ДНК) и IG-DMR двойным нокаутом (double knockout, DKO) при использовании бластоцист DKO-AG-haESCs можно с высокой эффективностью стабиль- 
но получать SC-животных, то есть DKO-AG-haESCs служит эквивалентом спермы. Важно, что DKO-AG-haESCs можно применять для множественных раундов генной модификации in vitro с целью создания генераций фертильных животных с заданными генетическими характеристиками. Таким образом, DKO-AG-haESCs («искусственные сперматозоиды»), измененные с помощью технологии CRISPR/Cas, могут стать удобным агентом оплодотворения для эффективного получения генетически модифицированного потомства и служить универсальным инструментом для анализа функции генов in vivo.

Тем не менее использование спермиев для доставки чужеродной ДНК в яйцеклетки в сочетании с CRISPR/Cas9 позволяет создавать трансгенную птицу в первом поколении, что значительно экономит время и ресурсы. Кроме того, разработанные методики могут быть легко адаптированы к различным видам птиц (67).

Классическая технология безвирусного трансгенеза - микроинъекция ДНК в зиготу. Ее применение на птице осложняется из-за слишком большого размера ооцита. Была изучена возможность инкубировать in vitro извлеченные из верхней части белкового отдела яйцевода оплодотворенные куриные яйцеклетки (68). Поскольку на этой стадии эмбрион является одноклеточным, теоретически возможно проведение микроинъекции чужеродной ДНК в такой эмбрион. Оплодотворенную куриную яйцеклетку можно культивировать в скорлупе с белком другого яйца (68). Метод включает три стадии (с учетом разных потребностей эмбриона в процессе развития) и предусматривает использование яичной скорлупы в качестве «сосуда» для культивирования. Начальный вариант предполагал культивирование в стеклянных сосудах в течение первых 24 ч с последующим перемещением эмбрионов из сосуда в сосуд (из скорлупы в скорлупу) для культивирования между I и II, II и III стадиями. В дальнейшем метод упростили культивированием эмбриона на I стадии развития в скорлупе, что исключило необходимость его переноса из стеклянного сосуда в скорлупу. В итоге количество жизнеспособных вылупившихся цыплят составило $20 \%$. Описанное культивирование или его отдельные стадии могут использоваться в различных экспериментальных целях, так как этот прием дает доступ к развивающемуся эмбриону на всех стадиях его развития (69).

Как метод создания трансгенной птицы рассматривалась возможность инъекции ДНК с дальнейшим культивированием эмбриона. Инъецировали генную конструкцию с репортерным геном $\beta$-галактозидазы. Экспрессию генной конструкции в первые 7 сут развития исследовали гистохимически по проявлению $\beta$-галактозидазной активности в эмбриональных тканях. Клетки с $\beta$-галактозидазной активностью наблюдали на стадии 250-500 клеток в центре бластодиска. На 2-е сут они были видны в больших долях бластодермы, на более поздних стадиях - в соответствующих меньших долях внезародышевых оболочек. Позитивные по $\beta$-галактозидазе клетки были в большинстве случаев рассеяны около примитивной полосы бластулы, но после гаструляции их наблюдали в эмбриональной ткани всего у 7 \% эмбрионов. Эти свидетельствует о транскрипционной активности на стадиях дробления и подтверждает данные о потере чужеродной ДНК в процессе раннего развития цыпленка. Результаты инъекции экзогенной ДНК на стадии одной клетки с дальнейшим культивированием эмбриона показали, что включение инъецированной ДНК в хромосомы цыпленка - достаточно редкое событие. Отсутствие интеграции в геном может быть маскировано наличием внехромосомных копий 
введенных плазмид (68).

Подход, успешно использованный при создании трансгенной птицы (70), представляет собой инъекцию генной конструкции в цитоплазму свежеоплодотворенной куриной яйцеклетки с ее инкубацией до вылупления. Яйцеклетки для инъекции извлекали из верхней части белкового отдела яйцевода уже покрытыми тонким слоем белка, но не скорлупой. Система культивирования была усовершенствована для оптимизации выживания инъецированной яйцеклетки. Система по-прежнему является трехстадийной, яичная скорлупа используется как сосуд для культивирования, жидкий белок, разбавленный раствором соли, - как питательная среда. На I стадии культивирования, продолжающейся 24 ч, инъецированную яйцеклетку помещают в скорлупу, содержащую такое количество питательной среды, чтобы зародышевый диск не был погружен в нее. На этой стадии эмбрион развивается от одной клетки до бластодермы (60 тыс. клеток), что характерно для снесенных оплодотворенных яиц. Далее скорлупа заполняется разбавленным яичным белком до полного погружения эмбриона, и окошко в скорлупе заклеивается липкой лентой. На этой, II стадии в течение 65 ч у эмбриона должно развиться сердце и внезародышевое кровообращение. На III, самой длительной стадии, продолжающейся до вылупления, содержимое скорлупы перемещают в другую, большую по размеру скорлупу. Это делается для создания воздушного пространства, необходимого в парафетальный период, когда эмбрион начинает дышать легкими и готовится к вылуплению. За 1-2 сут до вылупления, с началом легочной вентиляции, заклеивающая пленка перфорируется для свободного доступа воздуха в скорлупу. Затем пленка ослабляется, чтобы цыпленок мог выйти из скорлупы. Таким образом, инкубация на I стадии проходит в суррогате яйцевода - инкубаторе, где поддерживаются температура тела птицы $\left(42^{\circ} \mathrm{C}\right)$, высокая относительная влажность и высокая концентрация углекислого газа. В конце I стадии есть короткий период при комнатной температуре, чтобы имитировать снесение яйца. Условия инкубации в течение II и III стадий, эквивалентных периоду инкубации нормальных куриных яиц, изменяют по сравнению с традиционно используемыми в птицеводстве. Относительную влажность повышают примерно до 75 \% (до 18-х сут инкубации), затем ее уменьшают примерно до $65 \%$ (до стадии вылупления). В течение II стадии частоту поворотов увеличивают (4 раза в течение часа). На III стадии угол поворота уменьшают, чтобы эмбрион не касался липкой пленки, закрывающей окошко в скорлупе.

Создание трансгенных цыплят описанным методом - достаточно трудоёмко. Только 50 \% инъецированных яйцеклеток достигает III стадии, доля вылупившихся цыплят составляет около $15 \%$. Однако результаты анализа эмбрионов и цыплят на трансгенность обнадеживают. При использовании полимеразной цепной реакции (ПЦР), было показано, что ДНК почти 50\% эмбрионов и цыплят, достигших последних 12 сут культивирования, содержат трансген. Так у двух из вылупившихся цыплят обнаружили трансген в хориоаллантоисной мембране, пульпе ребра и крови. У одного из петушков трансген сохранился до половой зрелости. Его сперма содержала трансген (репортерный ген), который был передан 3,4 \% потомства, то есть 14 из 412 цыплят (70). Таким образом этим методом были созданы трансгенные куры и показано наследование трансгена. Все первичные трансгенные особи были мозаичными. В последующих поколениях наследование трансгена соответствовало с законам Менделя. По сообщениям авторов, до стадии вылупления доживало около 60 \% эмбрионов (70). Однако при п этой методики в других лабораториях аналогич- 
ный показатель не превышал 3-10 \% (71).

Другой вариант микроинъекций ДНК в яйцеклетки птиц предполагает образование третичных оболочек яйцеклетки (белка, подскорлупных и скорлупы) натуральным образом в яйцеводе птицы. Для доступа к овулировавшей куриной яйцеклетке необходимо установить время, когда следует вскрыть брюшную полость. У птицы, используемой в эксперименте (работа проводилась на курах породы белый леггорн в возрасте 180-300 сут), овуляция происходила через 20-25 мин после очередной яйцекладки. Примерно через 5 мин после овуляции яйцеклетка целиком находится в воронке яйцевода, где совершается ее оплодотворение. Время до полного перемещения яйцеклетки в белковый отдел составляет несколько минут. Извлеченную из брюшной полости или воронки яйцевода яйцеклетку инъецировали и помещали через воронку в белковый отдел яйцевода с применением специально разработанного расширителя или без него (72).

При овуляторном процессе у курицы непосредственно перед овуляцией воронка яйцевода активна. В этом состоянии она достаточно эластичная и прочная для того, чтобы поместить в нее трансплантируемую яйцеклетку. Активное состояние воронки наблюдается в течение примерно 5 мин, после чего она становится чрезвычайно рыхлой и повреждается при растяжении. В таких случаях или происходила потеря яйцеклетки изза механического повреждения при попытке возвратить ее в сжавшуюся воронку яйцевода, или трансплантация становилась невозможной из-за разрывов самой воронки. Только из половины имплантированных яйцеклеток получались морфологически нормальные яйца.

Для исключения стадий извлечения овулировавшей яйцеклетки и ее обратной имплантации в яйцевод было предложено проводить инъекции ДНК в бластодиск яйцеклеток через достаточно прозрачную оболочку воронки яйцевода. Вследствие этого потери яйцеклеток были сведены практически к нулю, а количество морфологически нормальных яиц приблизилось к $100 \%$. Таким образом, эффективность метода существенно возросла $(73,74)$.

Описанные выше приемы дают возможность получить не более одной жизнеспособной яйцеклетки, инъецированной инородной ДНК, от одной курицы за одну операцию. Вариантом, который позволил резко увеличить число таких яйцеклеток за каждую операцию, стало инъецирование в яйцеклетки, находящиеся в яичнике, то есть в фолликулы (75). В яичнике курицы имеется 4-5 крупных фолликулов, вполне пригодные для проведения микроинъекций. Однако при таком подходе возрастают технические трудности. Хирургический доступ к яичнику несколько сложнее, чем к яйцеводу, а оболочки фолликулов жестче и толще, чем у воронки яйцевода. Тем не менее положительные стороны предлагаемого варианта превалируют. К тому же отпадает необходимость устанавливать овуляторные циклы птицы, что упрощает подготовку и проведение эксперимента, а усложнение визуального контроля при проведении микроинъекций легко преодолимо благодаря применению современной офтальмологической и отоларингологической оптики и микротехники. Таким образом, гипотетически за каждую операцию от каждой курицы можно обработать и получить 4-5 инъецированных инородной ДНК яйцеклеток, причем без возможных проблем, связанных с неоплодотворением яйцеклеток или ненормальным формированием третичных оболочек.

Для оценки возможности проведения микроинъекций ДНК в фолликулы необходимо было убедиться, что из инъецированного фолликула 
действительно образуется яйцеклетка, а из нее - полноценное яйцо. Для этого в желток фолликулов вводили краситель - тушь или метиленовый синий. От прооперированных кур в течение 12 сут собирали и вскрывали яйца. Полученные результаты свидетельствовали, что из инъецированных фолликулов действительно формируются яйца. После 7-х сут краситель в яйцах ни разу не наблюдали. Необходимо отметить, что хирургическое вмешательство и инъекции могут нарушать порядок в иерархии фолликулов, согласно которой самый крупный фолликул должен овулировать первым. Довольно часто краситель обнаруживался в яйцах, снесенных не в числе первых, а позднее, несмотря на то, что его всегда вводили в три самых крупных фолликула. Вскрытие кур показало, что часть фолликулов рассасывается. Достаточно часто в яйцах отмечали лишь следы красителя, что означает его выведение из фолликула в процессе созревания. Вполне возможно, что некоторые яйца, отмеченные как не содержащие краситель, в действительности происходили из инъецированных фолликулов. Хотя полученные результаты недостаточно однозначны для строгих выводов об иерархии фолликулов, порядке их овуляции и т.д., можно заключить, что в среднем не менее 50 \% яиц, сносимых курами в первые 7 сут после операции, происходят из инъецированных фолликулов.

Разработанные хирургические операции и методы манипуляции с яйцеклеткой кур и перепелов позволяют проводить микроинъекции ДНК в яйцеклетку и обеспечивают ее дальнейшее нормальное эмбриональное развитие. С применением этих технологий были созданы трансгенные куры (76-78) с различными генными конструкциями и перепела с геном соматотропина крупного рогатого скота. При этом трансгенные перепела имели явные фенотипические отличия от нативных перепелов. Интеграция гена гормона роста крупнорогатого скота в геном перепелов способствовала повышению их иммунного статуса, что выражалось в ускоренной выработке антител. В качестве антигена использовался вакцинный штамм Ла-Сота вируса ньюкаслской болезни (79). Еще одной наиболее заметной фенотипической особенностью стали сносимые перепелами крупные яйца. Масса яиц в среднем по популяции экспериментальных перепелов на 20$50 \%$ превышала обычную. Живая масса трансгенных перепелов была на 5-15\% выше характерной как для породы, так и для контрольной группы нативных особей. Эти фенотипические признаки сохранились во всех 33 изученных поколениях потомков трансгенных перепелов (80).

Итак, в создании трансгенной птицы уже достигнуты определенные успехи на основе ряда методических подходов (ретровирусные и лентивирусные векторные системы, безвирусный трансгенез с использованием спермиев, «искусственных сперматозоидов», микроинъекций чужеродной ДНК в зиготу, свежеоплодотовренную яйцеклетку или фолликулы). Однако развитие трансгенеза в птицеводстве по большей части еще пока находится на раннем этапе, хотя на птице могут применяться все известные генно-инженерные технологии, в том числе активно разрабатываемые методы геномного редактирования, основанные на CRISPR/Cas9, которые близки к естественным механизмам действия этих систем в клетках. Современные лидеры в успешных разработках по редактированию генома - США, Китай, Великобритания; в России такие исследования также проводятся. Эта современная технология может быть полезна при решении спектра научно-практических проблем, включая создания новых пород сельскохозяйственной птицы. Тем не менее пока до конца не ясно, какие последствия несут в себе биоинженерные манипуляции с геномом, в том числе геном- 


\title{
ФНЦ Всероссийский научно-исследовательский \\ и технологический институт птииеводства РАН, \\ Поступила в редакцию \\ 7 октября 2019 года
}

141311 Россия, Московская обл., г. Сергиев Посад, ул. Птицеградская, 10,

e-mail: lg@vnitip.ru $\bowtie$, ruben@vnitip.ru, mail@vnitip.ru, fisinin@vnitip.ru

Sel'skokhozyaistvennaya biologiya [Agricultural Biology], 2019, V. 54, № 6, pp. 1080-1094

\section{TRANSGENIC POULTRY: DERIVATION AND AREAS OF APPLICATION (review)}

\author{
L.G. Korshunova, R.V. Karapetyan, O.F. Ziadinova, V.I. Fisinin
}

Federal Scientific Center All-Russian Research and Technological Poultry Institute RAS, 10, ul. Ptitsegradskaya, Sergiev Posad, Moscow Province, 141311 Russia, e-mail lg@vnitip.ru ( $₫$ corresponding author), ruben@vnitip.ru, mail@vnitip.ru, fisinin@vnitip.ru

ORCID:

Korshunova L.G. orcid.org/0000-0002-4393-7499

Karapetyan R.V. orcid.org/0000-0001-6610-7749

The authors declare no conflict of interests

Received October 7, 2019

Ziadinova O.F. orcid.org/0000-0003-1575-0093

Fisinin V.I. orcid.org/0000-0003-0081-6336

doi: 10.15389/agrobiology.2019.6.1080eng

\section{Abstract}

Transgenic poultry is a powerful instrument for the biotechnologic research in agriculture and medicine as well as a useful biological model (H. Sang, 2004). The technologies of transgenesis can be also aimed at the improvement of qualitative and quantitative characteristics of poultry products (L.G. Korshunova, 2011); development of poultry crosses genetically resistible to infectious diseases (L.G. Korshunova et al., 2014); derivation of poultry that can produce recombinant proteins of different usage areas within the eggs (D. Cao et al., 2015). The most popular way to induce transgenicity is the microinjection of foreign DNA into the ovicell in the proper moment when the organism consists of a single cell (zygote). Certain peculiarities of avian reproduction, however, constrain the induction of the transgenesis. A hen produces daily a single fertilized ovicell which is large in size and extremely sensitive to any manipulation like those to be performed on the mammal ovicells at the injection of foreign DNA. Furthermore, normal embryonic development in avian eggs requires the integrity of tertiary coats - albumen, inner shell membrane, and eggshell itself. The cleavage of chicken ovicell starts as early as in the magnum while freshly laid egg contains ca. 50,000-60,000 cells. As a consequence, first transgenic bird was produced via retroviral vectors. Retroviruses were the first contenders for the role of vectors in the gene transfer since they normally can enter the genomic DNA of the host with subsequent replication. At present the induction of retroviral (D.W. Salter et al., 1986; D.W. et al. Salter, 1987; D.W. et al. Salter, 1989; R.A. Bosselman et al., 1989; L.B. Crittenden, 1991; L.B. Crittenden et al., 1992) and lentiviral (H.A. Kaleri et al., 2011; A.H. Seidl et al., 2013; N.A. Volkova et al., 2015) transgenesis in chicken and quails was reported. The technologies of genomic modification in chicken and quails are continuing their development: e.g. the methods with the use of zinc finger nucleases (ZFNs), transcription activator-like effector nucleases (TALENs) (T.S. Park et al., 2014), CRISPR/Cas9 (I. Oishi et al., 2016; Q. Zuo et al., 2016) were developed. The CRISPR/Cas9 technology allows for the further progress in the genetic manipulations to produce genome-edited lines of poultry (N. Veron et al., 2015). Avian embryos, primarily chicken (Gallus gallus domesticus) and quail (Coturnix coturnix japonica), served as a model for the embryologic studies in vertebrates for more than a century. Modern targeted genetic manipulations in chicken embryo as an in vivo model became possible via the CRISPR/Cas9 editing system (V. Morin et al., 2017). The alternative non-viral methods of the induction of transgenesis in avian species can be used; one of these methods involves the transfer of foreign embryonic cells (as foreign DNA vector) into the recipient embryo resulting in the chimeric birds (J.N. Petitte et al., 1990; J.Y. Han et al., 2017; N.A. Volkova et al., 2017). Another attractive technology for the transfer of foreign genetic material into avian embryos involves the use of spermatozoa as the vectors since artificial insemination is the traditional and common technique for poultry (E. Harel-Markowitz et al., 2009; A.V. Samoylov et al., 2013). The combination of spermatozoa vectors and CRISPR/Cas9 technology can result in transgenesis in the first generation and hence allows for the substantial savings in time and resources (C.A. Cooper et al., 2017). The microinjection of DNA into the zygote is still a classic technology of non-viral transgenesis. The method involves direct injection of gene construct into the cytoplasm of freshly fertilized ovicell and subsequent incubation of injected eggs. The ovicell for injection should be taken immediately after its fertilization which means that its movement down the oviduct should be interrupted; further development of the injected embryo require special cultivation system (C. Mather, 1994). Another microinjection technique for avian ovicells involves natural for- 
mation of tertiary coats in the oviduct. The method is based on the surgical operation to get the access to the ovicell, its microinjection with foreign DNA, and implantation of injected ovicell back to the maternal oviduct for the formation of normal egg suitable for incubation (R.V. Karapetyan, 1995). The populations of transgenic chicken and quails with different foreign gene constructs were produced with the use of this method (R.V. Karapetyan, 1996; L.G. Korshunova et al., 2013).

Keywords: transgenesis, poultry, retroviruses, microinjection, primordial cells, sperm cells, genome editing.

\section{REFEREN CES}

1. Cao D., Wu H., Li Q., Sun Y., Liu T., Fei J., Zhao Y., Wu S., Hu X., Li N. Expression of recombinant human lysozyme in egg whites of transgenic hens. PLoS ONE, 2015, 10(2): e0118626 (doi: 10.1371/journal.pone.0118626).

2. Lin S.L., Chang S.E., Ying S.Y. Transgene-like animal models using intronic microRNAs In: MicroRNA protocols. Methods in molecular biology. V. 1733. S.Y. Ying (ed.). Humana Press, NY, 2018: 239-254 (doi: 10.1007/978-1-4939-7601-0_20).

3. Lee S.H., Gupta M.K., Ho Y.T., Kim T., Lee H.T. Transgenic chickens expressing human urokinase-type plasminogen activator. Poultry Science, 2013, 92(9): 2396-2403 (doi: 10.3382/ps.201303223).

4. Byun S.J., Ji M.R., Jang Y.J., Hwang A.I., Chung H.K., Kim J.S., Kim K.W., Chung H.J., Yang B.C., Jeon I., Park J.K., Yoo J.G., Kim T.Y. Human extracellular superoxide dismutase (EC-SOD) expression in transgenic chicken. BMB Reports, 2013, 46(8): 404-409 (doi: 10.5483/bmbrep.2013.46.8.251).

5. Sang H. Prospects for transgenesis in the chick. Mechanisms of Development, 2004, 121(9): 1179-1186 (doi: 10.1016/j.mod.2004.05.012).

6. Bosselman R.A., Hsu R.-Y., Boggs T., Hu S., Bruszewski J., Ou S., Kozar L., Martin F., Green C., Jacobsen F., Nicholson M., Schultz J.A., Semon K.M., Rishell W., Stewart, R.G. Germline transmission of exogenous genes in the chicken. Science, 1989, 243(4890): 533-535 (doi: 10.1126/science.2536194).

7. Crittenden L.B. Retroviral elements in the genome of the chicken: implications for poultry genetics and breeding. Critical Reviews of Poultry Biology, 1991, 3(2): 73-109.

8. Salter D.W., Smith E.J., Hughes S.H., Wright S.E., Crittenden L.B. Transgenic chickens: insertion of retroviral genes into the chicken germ line. Virology, 1987, 157(1): 236-240 (doi: 10.1016/0042-6822(87)90334-5).

9. Salter D.W., Smith E.J., Hughes S.H., Wright S.E., Fadly A.M., Witter R.L., Crittenden L.B. Gene insertion into the chicken germ line by retroviruses. Poultry Science, 1986, 65(8): 14451458 (doi: 10.3382/ps.0651445).

10. Salter D.W., Crittenden L.B. Artificial insertion of a dominant gene for resistance to avian leukosis virus into the germ line of the chicken. Theoretical and Applied Genetics, 1989, 77(4): $457-$ 461 (doi: 10.1007/BF00274263).

11. Crittenden L.B., Salter D.W. A transgene, alv6, that expresses the envelope of subgroup A avian leukosis virus reduces the rate of congenital transmission of a field strain of avian leukosis virus. Poultry Science, 1992, 71(5): 799-806 (doi: 10.3382/ps.0710799).

12. Petropoulos C.J., Payne W., Salter D.W., Hughes S.H. Appropriate in vivo expression of a muscle-specific promoter by using avian retroviral vectors for gene transfer [corrected]. Journal of Virology, 1992, 66(6): 3391-3397.

13. Poynter G., Huss D., Lansford R. Japanese quail: an efficient animal model for the production of transgenic avians. Cold Spring Harbor Protocols, 2009, 2009(1): pdb emo112 (doi: 10.1101/pdb.emo112).

14. McGrew M.J., Sherman A., Lillico S.G., Taylor L., Sang H. Functional conservation between rodents and chicken of regulatory sequences driving skeletal muscle gene expression in transgenic chickens. BMC Developmental Biology, 2010, 10: 26 (doi: 10.1186/1471-213X-10-26).

15. Kwon M.S., Koo B.C., Choi B.R., Park Y.Y., Lee Y.M., Suh H.S., Park Y.S., Lee H.T., Kim J.H., Roh J.Y., Kim N.H., Kim T. Generation of transgenic chickens that produce bioactive human granulocyte-colony stimulating factor. Molecular Reproduction and Development, 2008, 75(7): 1120-1126 (doi: 10.1002/mrd.20860).

16. Scott B.B., Lois C. Generation of tissue-specific transgenic birds with lentiviral vectors. Proceedings of the National Academy of Sciences, 2005, 102(45): 16443-16447 (doi: 10.1073/pnas.0508437102).

17. Ayers K.L., Smith C.A., Lambeth L.S. The molecular genetics of avian sex determination and its manipulation. Genesis, 2013, 51(5): 325-336 (doi: 10.1002/dvg.22382).

18. Seidl A.H., Sanchez J.T., Schecterson L., Tabor K.M., Wang Y., Kashima D.T., Poynter G., Huss D., Fraser S.E., Lansford R., Rubel E.W. Transgenic quail as a model for research in the avian nervous system: a comparative study of the auditory brainstem. The Journal of Comparative Neurology, 2013, 521(1): 5-23 (doi: 10.1002/cne.23187).

19. Park F. Lentiviral vectors: are they the future of animal transgenesis? Physiological Genomics, 
2007, 31(2): 159-173 (doi: 10.1152/physiolgenomics.00069.2007).

20. Intarapat S., Stern C.D. Chick stem cells: current progress and future prospects. Stem Cell Research, 2013, 11(3): 1378-1392 (doi: 10.1016/j.scr.2013.09.005).

21. Byun J.S., Yuk S.S., Jang Y.J., Choi H., Jeon M.H., Erdene-Ochir T.O., Kwon J.H., Noh J.Y., Kim J.S., Yoo J.G., Song C.S. Transgenic chickens expressing the 3D8 single chain variable fragment protein suppress avian influenza transmission. Scientific Reports, 2017, 7(1): 5938 (doi: 10.1038/s41598-017-05270-8).

22. Kaleri H.A., Xu S.Y., Lin H.L. Generation of transgenic chicks using an oviduct-specific expression system. Genetics and Molecular Research, 2011, 10(4): 3046-3055 (doi: 10.4238/2011.December.8.1).

23. Volkova N.A., Fomin I.K., Tomgorova E.K., Vetokh A.N., Mennibaeva E.R., Brem G., Zinov'eva N.A. The study of factors affected the gene transfer efficiency in chicken embryonic cells by application of lentiviral vectors. Agricultural Biology [Sel'skokhozyaistvennaya biologiya], 2015, 50(4): 458-466 (doi: 10.15389/agrobiology.2015.4.458eng).

24. Park S.H., Kim J.N., Park T.S., Lee S.D., Kim T.H., Han B.K., Han J.Y. CpG methylation modulates tissue-specific expression of a transgene in chickens. Theriogenology, 2010, 74(5): 805-816.e1 (doi: 10.1016/j.theriogenology.2010.04.005).

25. Park T.S., Lee H.G., Moon J.K., Lee H.J., Yoon J.W., Yun B.N., Kang S.C., Kim J., Kim H., Han J.Y., Han B.K. Deposition of bioactive human epidermal growth factor in the egg white of transgenic hens using an oviduct-specific minisynthetic promoter. The FASEB Journal, 2015, 29(6): 2386-2396 (doi: 10.1096/fj.14-264739).

26. Park T.S., Lee H.J., Kim K.H., Kim J.S., Han J.Y. Targeted gene knockout in chickens mediated by TALENs. Proceedings of the National Academy of Sciences, 2014, 111(35): 12716-12721 (doi: 10.1073/pnas.1410555111).

27. Oishi I., Yoshii K., Miyahara D., Kagami H., Tagami T. Targeted mutagenesis in chicken using CRISPR/Cas9 system. Scientific Reports, 2016, 6: 23980 (doi: 10.1038/srep23980).

28. Zuo Q., Wang Y., Cheng S., Lian C., Tang B., Wang F., Lu Z., Ji Y., Zhao R., Zhang W., Jin K., Song J., Zhang Y., Li B. Site-directed genome knockout in chicken cell line and embryos can use CRISPR/Cas gene editing technology. G3: Genes, Genomes, Genetics, 2016, 6(6): 1787-1792 (doi: 10.1534/g3.116.028803).

29. Davey M.G., Balic A., Rainger J., Sang H.M., McGrew M.J. Illuminating the chicken model through genetic modification. Int. J. Dev. Biol., 2018, 62: 257-264 (doi: 10.1387/ijdb.170323mm).

30. Fineran P.C., Charpentier E. Memory of viral infections by CRISPR-Cas adaptive immune systems: acquisition of new information. Virology, 2012, 434(2): 202-209 (doi: 10.1016/j.virol.2012.10.003).

31. Jinek M., Chylinski K., Fonfara I., Hauer M., Doudna J.A., Charpentier E. A programmable dual-RNA-guided DNA endonuclease in adaptive bacterial immunity. Science, 2012, 337(6096): 816-821 (doi: 10.1126/science.1225829).

32. Wiedenheft B., Sternberg S.H., Doudna J.A. RNA-guided genetic silencing systems in bacteria and archaea. Nature, 2012, 482(7385): 331-338 (doi: 10.1038/nature10886).

33. Cox D.B.T., Platt R.J., Zhang F. Therapeutic genome editing: prospects and challenges. Nature Medicine, 2015, 21(2): 121-131 (doi: 10.1038/nm.3793).

34. Ramanan V., Shlomai A., Cox D.B.T., Schwartz R.E., Michailidis E., Bhatta A., Scott D.A., Zhang F., Rice C.M., Bhatia S.N. CRISPR/Cas9 cleavage of viral DNA efficiently suppresses hepatitis B virus. Scientific Reports, 2015, 5: 10833 (doi: 10.1038/srep10833).

35. Véron N., Qu Z., Kipen P.A.S., Hirst C.E., Marcelle C. CRISPR mediated somatic cell genome engineering in the chicken. Developmental Biology, 2015, 407(1): 68-74 (doi: 10.1016/j.ydbio.2015.08.007).

36. Abu-Bonsrah K.D., Zhang D., Newgreen D.F. CRISPR/Cas9 targets chicken embryonic somatic cells in vitro and in vivo and generates phenotypic abnormalities. Scientific Reports, 2016, 6: 34524 (doi: 10.1038/srep34524).

37. Cheng Y., Lun M., Liu Y., Wang H., Yan Y., Sun J. CRISPR/Cas9-mediated chicken TBK1 gene knockout and its essential role in STING-mediated IFN-beta induction in chicken cells. Frontiers in Immunology, 2018, 9: 3010 (doi: 10.3389/fimmu.2018.03010).

38. Tang N., Zhang Y., Pedrera M., Chang P., Baigent S., Moffat K., Shen Z., Nair V., Yao Y. A simple and rapid approach to develop recombinant avian herpesvirus vectored vaccines using CRISPR/Cas9 system. Vaccine, 2018, 36(5): 716-722 (doi: 10.1016/j.vaccine.2017.12.025).

39. Williams R.M., Senanayake U., Artibani M., Taylor G., Wells D., Ahmed A.A., SaukaSpengler T. Genome and epigenome engineering CRISPR toolkit for in vivo modulation of cisregulatory interactions and gene expression in the chicken embryo. Development, 2018, 145(4): dev160333 (doi: 10.1242/dev.160333).

40. Gandhi S., Piacentino M.L., Vieceli F.M., Bronner M.E. Optimization of CRISPR/Cas9 genome editing for loss-of-function in the early chick embryo. Developmental Biology, 2017, 432(1): 86-97 (doi: 10.1016/j.ydbio.2017.08.036).

41. Morin V., Véron N., Marcelle C. CRISPR/Cas9 in the chicken embryo. In: Avian and reptilian developmental biology. Methods in molecular biology, vol. 1650. G. Sheng (ed.). Humana Press, NY, 2017: 113-123 (doi: 10.1007/978-1-4939-7216-6_7).

42. Hirst C.E., Serralbo O., Ayers K.L., Roeszler K.N., Smith C.A. Genetic manipulation of the 
avian urogenital system using in ovo electroporation. In: Avian and reptilian developmental biology. Methods in molecular biology, vol. 1650. G. Sheng (ed.). Humana Press, NY, 2017: 177-190 (doi: 10.1007/978-1-4939-7216-6 11).

43. Petitte J.N., Clark M.E., Liu G., Verrinder Gibbins A.M., Etches R.J. Production of somatic and germline chimeras in the chicken by transfer of early blastodermal cells. Development, 1990, 108(1): 185-189.

44. Han J.Y., Lee B.R. Isolation and characterization of chicken primordial germ cells and their application in transgenesis. In: Avian and reptilian developmental biology. Methods in molecular biology, vol. 1650. G. Sheng (ed.). Humana Press, NY, 2017: 229-242 (doi: 10.1007/978-1-4939-7216-6_15).

45. Volkova N.A., Bagirov V.A., Tomgorova E.K., Vetokh A.N., Volkova L.A., Zinov'eva N.A. Isolation, cultivation and characterization of quail primordial germ cells. Agricultural Biology [Sel'skokhozyaistvennaya biologiya], 2017, $261-267$ (doi: 10.15389/agrobiology.2017.2.261eng).

46. Choi H.J., Lee H.C., Kang K.S., Lee H.G., Ono T., Nagai H., Sheng G., Han J.Y. Production of interspecific germline chimeras via embryo replacement. Biology of Reproduction, 2015, 93(2): Article 36 (doi: 10.1095/biolreprod.114.127365).

47. Haraguchi S., Matsubara Y., Hosoe M. Chick embryos can form teratomas from microinjected mouse embryonic stem cells. Develop. Growth Differ., 2016, 58(2): 194-204 (doi: 10.1111/dgd.12260).

48. Brazolot C.L., Petitte J.N., Etches R.J., Verrinder Gibbins A.M. Efficient transfection of chicken cells by lipofection, and introduction of transfected blastodermal cells into the embryo. Molecular Reproduction and Development, 1991, 30(4): 304-312 (doi: 10.1002/mrd.1080300404).

49. Petitte J.N., Karagenc L., Ginsburg M. The origin of the avian germ line and transgenesis in birds. Poultry Science, 1997, 76(8): 1084-1092 (doi: 10.1093/ps/76.8.1084).

50. Etches R.J. Transgenic chickens. Proc. 10th European poultry conference «The poultry industry towards the 21st century». Jerusalem, Israel, 1998: 3-6.

51. Savva D., Page N., Vick L., Simkiss K. Detection of foreign DNA in transgenic chicken embryos using the polymerase chain reaction. Research in Veterinary Science, 1991, 50(2): 131-133 (doi: 10.1016/0034-5288(91)90094-5).

52. Petitte J.N., Liu G., Yang Z. Avian pluripotent stem cells. Mechanisms of Development, 2004, 121(9): 1159-1168 (doi: 10.1016/j.mod.2004.05.003).

53. Song Y., Duraisamy S., Ali J., Kizhakkayil J., Jacob V.D., Mohammed M.A., Eltigani M.A., Amisetty S., Shukla M.K., Etches R.J., de Lavoir M.C. Characteristics of long-term cultures of avian primordial germ cells and gonocytes. Biology of Reproduction, 2014, 90(1): Article 15 (doi: 10.1095/biolreprod.113.113381).

54. Leighton P.A., van de Lavoir M.C., Diamond J.H., Xia C., Etches R.J. Genetic modification of primordial germ cells by gene trapping, gene targeting, and phiC31 integrase. Molecular Reproduction and Development, 2008, 75(7): 1163-1175 (doi: 10.1002/mrd.20859).

55. Motono M., Yamada Y., Hattori Y., Nakagawa R., Nishijima K., Iijima S. Production of transgenic chickens from purified primordial germ cells infected with a lentiviral vector. Journal of Bioscience and Bioengineering, 2010, 109(4): 315-321 (doi: 10.1016/j.jbiosc.2009.10.007).

56. Nakamura Y., Usui F., Ono T., Takeda K., Nirasawa K., Kagami H., Tagami T. Germline replacement by transfer of primordial germ cells into partially sterilized embryos in the chicken. Biology of Reproduction, 2010, 83(1): 130-137 (doi: 10.1095/biolreprod.110.083923).

57. Park K.J., Kang S.J., Kim T.M., Lee Y.M., Lee H.C., Song G., Han J.Y. Gamma-irradiation depletes endogenous germ cells and increases donor cell distribution in chimeric chickens. In Vitro Cell. Dev. Biol.-Animal, 2010, 46(10): 828-833 (doi: 10.1007/s11626-010-9361-8).

58. Nakamura Y., Usui F., Miyahara D., Mori T., Ono T., Kagami H., Takeda K., Nirasawa K., Tagami T. X-irradiation removes endogenous primordial germ cells (PGCs) and increases germline transmission of donor PGCs in chimeric chickens. Journal of Reproduction and Development, 2012, 58(4): 432-437 (doi: 10.1262/jrd.2012-045).

59. Song Y., D'Costa S., Pardue S.L., Petitte J.N. Production of germline chimeric chickens following the administration of a busulfan emulsion. Molecular Reproduction and Development, 2005, 70(4): 438-444 (doi: 10.1002/mrd.20218).

60. Nakamura Y., Yamamoto Y., Usui F., Atsumi Y., Ito Y., Ono T., Takeda K., Nirasawa K., Kagami H., Tagami T. Increased proportion of donor primordial germ cells in chimeric gonads by sterilisation of recipient embryos using busulfan sustained-release emulsion in chickens. $R e$ production, Fertility, and Development, 2008, 20(8): 900-907 (doi: 10.1071/rd08138).

61. Mucksová J., Reinišová M., Kalina J., Lejčková B., Hejnar J., Trefil P. Conservation of chicken male germline by orthotopic transplantation of primordial germ cells from genetically distant donorsdagger. Biology of Reproduction, 2019, 101(1): 200-207 (doi: 10.1093/biolre/ioz064).

62. Harel-Markowitz E., Gurevich M., Shore L.S., Katz A., Stram Y., Shemesh M. Use of sperm plasmid DNA lipofection combined with REMI (restriction enzyme-mediated insertion) for production of transgenic chickens expressing eGFP (enhanced green fluorescent protein) or human follicle-stimulating hormone. Biology of Reproduction, 2009, 80(5): 1046-1052 (doi: 
10.1095/biolreprod.108.070375).

63. Samoilov A.V., Kesyan A.Z., Suraeva N.M. Izvestiya Rossiiskoi akademii nauk. Seriya biologicheskaya, 2013, 5: 517-521 (doi: 10.7868/S0002332913040140) (in Russ.).

64. Korshunova L.G., Karapetyan R.V., Ziadinova O.F. Ptitsevodstvo, 2017, 4: 22-25 (in Russ.).

65. Chaparian S., Abdulahnejad A., Rashidi F., Toghyani M., Gheisari A., Eghbalsaied S. Is passive transmission of non-viral vectors through artificial insemination of sperm-DNA mixtures sufficient for chicken transgenesis? Journal of Reproduction and Development, 2016, 62(3): 265-270 (doi: 10.1262/jrd.2015-176).

66. Wang L., Li J. “Artificial spermatid”-mediated genome editing. Biology of Reproduction, 2019, 101(3): 538-548 (doi: 10.1093/biolre/ioz087).

67. Cooper C.A., Challagulla A., Jenkins K.A., Wise T.G., O'Neil T.E., Morris K.R., Tizard M.L., Doran T.J. Generation of gene edited birds in one generation using sperm transfection assisted gene editing (STAGE). Transgenic Research, 2017, 26(3): 331-347 (doi: 10.1007/s11248-016-0003-0).

68. Sang H.M., Perry M.M., Gribbin C., Mather C., Morrice D., Love J. Chick embryo culture and gene transfer. In: AFRC Institute of Animal Physiology and Genetics Research. Report for 1990-1991. R.B. Heap, H.D. Griffin, G. Leng et al. (eds.). Agricultural and Food Research Council, Cambridge, 1992: 52-53.

69. Andacht T., Hu W., Ivarie R. Rapid and improved method for windowing eggs accessing the stage X chicken embryo. Molecular Reproduction and Development, 2004, 69(1): 31-34 (doi: 10.1002/mrd.20155).

70. Mather C. Transgenic chicken by DNA microinjection. Poultry International, 1994, 33(6): 16-18.

71. Ellendorff F., Gulyas N., Muhlbauer E., Klein S. Potential use of molecular sex recognition in layer birds. Proc. XX World's Poultry Congress. New Delhi, India, 1996: 3-4.

72. Ernst L.K., Fisinin V.I., Zhuravlev I.V., Karapetyan R.V., Matveenko N.P., Ziadinova O.F., Kudryavtsev I.V., Kuzin B.A., Enikolopov G.N. Sposob transplantatsii kurinoi yaitsekletki. Pat. 1565025 SU. № 4396482. Zayavl. 23.03.88. Opubl. 15.01.90. Byul. № 1 [Method for chicken egg transplantation. Patent 1565025 SU. № 4396482. Claims 23.03.88. Publ. 15.01.90. Bul. № 1] (in Russ.).

73. Karapetyan R.V. Doklady RASKHN, 1995, 4: 27-29 (in Russ.).

74. Karapetyan R.V. Doklady RASKHN, 1996, 2: 19-20 (in Russ.).

75. Fisinin V.I., Ernst L.K., Karapetyan R.V., Matveenko N.P., Zazykina T.V., Ziadinova O.F., Zhadanov A.B. Sposob povysheniya yaichnoi produktivnosti ptitsy. Pat. 2061366 RU. № 93019970/15. Zayavl. 19.04.93. Opubl. 10.06.96. Byul. № 16 [Method for increase egg productivity of poultry. Patent 2061366 RU. № 93019970/15. Claims 19.04.93. Publ. 10.06.96. Bul. № 16] (in Russ.).

76. Korshunova L.G., Karapetyan R.V., Fisinin V.I. Methods for genetic modification in poultry (review). Agricultural Biology [Sel'skokhozyaistvennaya biologiya], 2013, 6: 3-15 (in Russ.).

77. Korshunova L.G., Fisinin V.I., Karapetyan R.V. Ptitsa $i$ ptitseprodukty, 2015, 2: 47-49 (in Russ.).

78. Korshunova L.G., Karapetyan R.V., Ziadinova O.F. Modification of chicken genome by interferon gene. Russian Agricultural Sciences, 2014, 40(5): 379-381 (doi: 10.3103/s1068367414050140).

79. Korshunova L.G., Karapetyan R.V. Veterinariya, 2009, 5: 15-16 (in Russ.).

80. Korshunova L.G. Biological and productive properties of quails transgenic on bovine somatotropin gene. Agricultural Biology [Sel'skokhozyaistvennaya biologiya], 2011, 2: 46-50 (in Engl.). 